\title{
BKV-infection in kidney graft dysfunction
}

Authors

Juliana Montagner ${ }^{1,2}$ Tatiana Michelon ${ }^{1,2}$ Barbara Fontanelle Alexandre Oliveira ${ }^{1}$ Janaina Silveira ${ }^{1,2}$ Regina Schroeder ${ }^{1,2}$ Jorge Neumann ${ }^{2}$ Elizete Keitel ${ }^{1}$ Claudio Osmar Pereira Alexandre ${ }^{1}$

Post-Graduation in Pathology - Universidade Federal de Ciências da Saúde de Porto Alegre ${ }^{2}$ Transplant Immunology Laboratory - Santa Casa de Porto Alegre Hospital, RS, Brazil
Submitted on: 04/01/2009 Approved on: 06/14/2009

\section{Correspondence to:} Juliana Montagner, Rua Coronel Corte Real 311/702 - Petrópolis Porto Alegre - RS - Brazil CEP: 90630-080 E-mail: jmontagner@ mixmail.com

This study received financial support from Coordenação de Aperfeiçoamento de Pessoal de Nível Superior (CAPES).

\begin{abstract}
Introduction: BKV nephropathy (BKN) causes kidney graft loss, whose specific diagnosis is invasive and might be predicted by the early detection of active viral infection. Objective: Determine the $\mathrm{BKV}$-infection prevalence in late kidney graft dysfunction by urinary decoy cell (DC) and viral DNA detection in urine (viruria) and blood (viremia; active infection). Methods: Kidney recipients with $>1$ month follow-up and creatinine $>1.5 \mathrm{mg} / \mathrm{dL}$ and/or recent increasing $>20 \%(\mathrm{n}=120)$ had their urine and blood tested for BKV by semi-nested PCR, DC searching, and graft biopsy. PCR-positive patients were classified as $1+, 2+, 3+$. DC, viruria and viremia prevalence, sensitivity, specificity, and likelihood ratio (LR) were determined (Table $2 \times 2$ ). Diagnosis efficacy of DC and viruria were compared to viremia. Results: DC prevalence was 25\%, viruria $61.7 \%$, and viremia $42.5 \%$. Positive and negative patients in each test had similar clinical, immunossupressive, and histopathological characteristics. There was no case of viremia with chronic allograft nephropathy and, under treatment with sirolimus, patients had a lower viruria prevalence $(\mathrm{p}=0.043)$. Intense viruria was the single predictive test for active infection $(3+; \mathrm{LR}=2.8) .{ }^{1,6-4,9}$ Conclusion: DC, BKV-viruria and -viremia are commun findings under late kidney graft dysfunction. Viremia could only be predicted by intense viruria. These results should be considered under the context of BKN confirmation.
\end{abstract}

Keywords: BK virus, decoy cells, kidney transplantation, PCR, viremia, viruria.

[Braz J Infect Dis 2010;14(2):170-174] @Elsevier Editora Ltda.

\section{INTRODUCTION}

Opportunistic infections are a major cause of morbidity after transplantation. Such fact has stimulated studies toward virus epidemiology, biology, and pathogenic effects among this high risk population. ${ }^{1} \mathrm{BK}$ virus (BKV), a member of the Polyomavirus family, is a common viral infection, as cytomegalovirus, which is associated with high risk of renal disorder after kidney transplantation. ${ }^{2}$

The primary infection occurs during early childhood, and becomes latent in the kidneys. As soon as the immunosuppression starts at the time of transplantation, the virus can reactivate and develop a clinically relevant disease, which is manifested as tubulointersticial nephritis (known as BKV nephropathy [BKN] and/or ureteral stenosis). ${ }^{3-6}$

BKN has been associated with graft dysfunction in $3 \%$ to $14 \%$ of kidney recipients, leading to graft failure in up to $67 \%$ of the cases. $^{2,7,8}$ Specific diagnosis of BKN depends on the pathological tissue patterns on the graft bi- opsy specimen, which can be confounded with cellular rejection mainly when both pathologies coexist. Thus, BKN diagnosis, based exclusively on the pathological criteria, might be difficult. $^{4-11}$

This study was designed to investigate the prevalence of BKV infection among patients under late kidney graft dysfunction. It combines three non-invasive methodologies: urinary cytology (looking for decoy cells; DC), viruria (urinary viral DNA), and viremia (active infection; blood viral DNA), and takes into consideration the importance of an early diagnosis and the need of graft biopsy invasiveness to define a suspicion of BKN.

\section{PATIENTS AND METHODS}

\section{Patients}

Kidney transplant recipients $(\mathrm{n}=120)$, from living or deceased donors, with serum creatinine levels above $1.5 \mathrm{mg} / \mathrm{dL}$ or recent increase of $>20 \%{ }^{2,12}$ were allocated during 1 year of 
outpatient follow-up. After signing an informed consent, previously approved by the local Ethic Committee, patients performed a graft biopsy, and urine and blood samples were collected. Patients who refuse to participate, those younger than 18 years old or less than 1 month of post-transplant follow-up, and patients with a known and reversible cause for graft dysfunction were excluded from the study.

\section{Urinary cytology}

Papanicolau standard staining was performed in urinary sediment. DC were recognized for their typical round-glass intranuclear inclusions with a peripheral of hyperchromatic chromatin. ${ }^{13-15}$

\section{Molecular biology}

\section{DNA extraction}

Pellet urinary sediment was used for DNA extraction following the protocol previously published by Takayama et al. ${ }^{4}$ Blood samples collected in EDTA anticoagulant were submitted to DNA extraction using a commercial kit (PureLinkGenomic, Invitrogen, USA).

\section{Polymerase Chain Reaction (PCR)}

Semi-nested PCR was performed in order to detect the BKV DNA, as validated by Nickeleit et al..$^{13}$ The outer primer pair, 5' AAGTCTTTAGGGTCTTCTAC 3' and 5' GTGCCAACCTATGGAACAGA 3', was used to generate a 176-bp, a common amplicon among Polyomaviridae memberships. It was used the primer 5' AAGTCTTTAGGGTCTTCTAC 3' with 5' GAGTCCTGGTGGAGTTCC 3' in order to obtain a 149-bp fragment, a specific BKV-region. ${ }^{16}$

A spectrophotometer, using a $260 \mathrm{~nm}$ length wave (Bio Photometer, Eppendorf, Germany), was used to standardize the total DNA content at 0.5 and $0.1 \mu \mathrm{g}$ in blood and urine samples, respectively, for PCR reaction. Amplification steps were performed from a $25 \mu \mathrm{l}$ reaction-mixture containing $1.5 \mathrm{mM} \mathrm{MgCl}_{2}, 0.5 \mu \mathrm{M}$ of each primer, dNTPs $200 \mu \mathrm{M}$ and $2.5 \mathrm{U}$ of Taq polymerase (Invitrogen, Brazil).

The reaction program consisted of 5 minute-denaturation at $94^{\circ} \mathrm{C}$ and were followed by 35 cycles of denaturation at $94^{\circ} \mathrm{C}$ during 1 minute, annealing at $56^{\circ} \mathrm{C}$ for 1 minute and extension at $72^{\circ} \mathrm{C}$ for 5 minutes. A final extension at $72^{\circ} \mathrm{C}$ for 10 minutes was added.

Free DNA samples were analyzed as negative controls, and DNA obtained from a known BKV-positive patient was used as positive control in each test. All negative tests had their content and quality DNA certified by amplification using a primer for $\beta$-globine detection.

\section{Semi-quantitative PCR analysis}

The amplified regions were detected in agarose gel 2.5\% stained with ethidium bromide. The amplified urine and blood products were qualified as $1+, 2+, 3+$, according to that observed at the transilluminator, corresponding, respectively, to weak, intermediate, and strong intensity of amplification.

\section{Histology}

All biopsies were classified according to Banff criteria 1997 for kidney graft pathologies definition. ${ }^{17}$

\section{Statistical analysis}

Data were expressed as percentage, mean and standard deviation or median and range. Comparisons of age and creatinine levels were performed by Student's t-test. Other characteristics and risk factors of patients were analyzed by Chi-squared or Fisher's exact test, as indicated. Sensitivity and specificity were described as percentage and likelihood ratio (LR), and were calculated by using Table $2 \times 2$. For study purposes, DC and viruria values were compared with the presence of BKV DNA in peripheral blood. The software Statistical Package for Social Sciences 14.0 was used for all statistical analysis, being significant $\mathrm{p}$ values $\leq 0.05$ and confidence intervals $95 \%$.

\section{RESULTS}

Among the 120 kidney recipients under late graft dysfunction, the prevalence of DC was $25.0 \%$ (95\% CI: 17.5-33.7), viruria $61.7 \%$ (95\% CI: 52.4-70.4), and viremia $42.5 \%$ (95\% CI: 33.5-51.9). Serum creatinine $2.3 \mathrm{mg} / \mathrm{dL}(0.8-8.5 \mathrm{mg} / \mathrm{dL})$, and median follow-up was 1.6 years.

There was predominance of male gender $60.8 \%(n=73 / 120)$ and $56.7 \%$ were recipients from deceased donors $(n=68 / 120)$. Patients receiving a second or third allograft represented $10.0 \%$ of the sample (12/120), and there was $16.7 \%(17 / 102)$ of anti-HLA class I pre-sensitized patients. Induction with immunosuppressants had been used by $15.0 \%$ (18/120) of them at the time of transplantation, and current prophylatic immunosuppressive scheme was a combination of the following drugs: prednisone $(\mathrm{n}=103 ; 94.2 \%)$, mofetil mycofenolate $(n=80 ; 66.7 \%)$, tacrolimus $(n=60 ; 50.0 \%)$, cyclosporine $(\mathrm{n}=55 ; 45.8 \%)$, azatioprine $(\mathrm{n}=24 ; 20.0 \%)$, and sirolimus $(\mathrm{n}=14 ; 11.7 \%)$. General characteristics are presented in Table 1.

Clinical characteristics, pre-transplant immunological risk, current immunosuppressive protocol, and kidney histopathology findings were similar among negative and positive patients, taking into consideration each laboratory test performed. An exception was the higher rate of patients treated with sirolimus, showing a lower prevalence of positive urine BKV-DNA detection $(\mathrm{p}=0.043)$. Another difference was observed among patients with current diagnosis of chronic allograft nephropathy (CAN). In this group, no case of BKV-DNA in peripheral blood $\mathrm{p}=0.020$ ) was detected.

Table 2 describes the comparison of diagnostic efficacy of urinary cytopathic effect (DC) and BKV-viruria with 
Table 1. Clinical characteristics of kidney transplant recipients under late graft dysfunction studied for $B K V$ infection

\begin{tabular}{lll}
\hline Recipient's Characteristics* & \multicolumn{2}{c}{ n (\%) } \\
\hline Male gender & 73 & 60.8 \\
\hline Re-transplant & 12 & 10.0 \\
\hline Pre-sensitization*** & 17 & 16.7 \\
\hline Deceased donor & 68 & 56.7 \\
\hline Induction therapy**** & 18 & 15.0 \\
\hline Previous CMV disease & 34 & 28.3 \\
\hline Previous AR & 19 & 15.2 \\
\hline Previous CAN & 14 & 11.7 \\
\hline CyA-Aza-Pred & 17 & 14.2 \\
\hline CyA-MMF-Pred & 31 & 25.8 \\
\hline FK-MMF-Pred & 44 & 36.7 \\
\hline FK-Sirol-Pred & 10 & 8.3 \\
\hline
\end{tabular}

$* \mathrm{n}=120$

$* *$ patients evaluated for anti-HLA antibodies before transplantation $(\mathrm{n}=102)$

$* * *$ basiliximab

CMV: cytomegalovirus

AR: acute rejection defined by biopsy

CAN: chronic allograft nephropathy

CyA: cyclosporine

Aza: azatioprine

Pred: prednisone

MMF: mofetil mycofenolate

FK: tacrolimus

Sirol: sirolimus.

Table 2. Comparison of diagnostic efficacy of urinary cytopatic effect (DC) and BKV-viruria with BKV-viremia in kidney transplant recipients under late graft dysfunction

\begin{tabular}{|c|c|c|c|c|c|}
\hline & $\begin{array}{c}\text { BKV viremia + } \\
\text { n (\%) }\end{array}$ & $\begin{array}{c}\text { BKV viremia - } \\
\text { n (\%) }\end{array}$ & LR & 95\% CI & $\begin{array}{c}\text { Post test } \\
\text { probability (\%) }\end{array}$ \\
\hline \multicolumn{6}{|l|}{ Urine BKV PCR (1) } \\
\hline Negative & $11(21.6)$ & $35(50.7)$ & 0.43 & $0.24-0.75$ & 24.1 \\
\hline $1+(2)$ & $5(9.8)$ & $14(20.3)$ & 0.48 & $0.19-1.26$ & 26.2 \\
\hline $2+(2)$ & $8(15.7)$ & $7(10.1)$ & 1.55 & $0.60-3.99$ & 53.4 \\
\hline $3+(2)$ & $27(52.9)$ & $13(18.8)$ & 2.81 & $1.61-4.89$ & 67.5 \\
\hline \multicolumn{6}{|l|}{ Decoy Cells (DC) ${ }^{(3)}$} \\
\hline Negative & $35(68.6)$ & $55(79.7)$ & 0.86 & $0.69-1.07$ & 38.9 \\
\hline Positive & $16(31.4)$ & $14(20.3$ & 1.55 & $0.83-2.87$ & 53.3 \\
\hline
\end{tabular}

Viruria: urine BKV PCR

Viremia: peripheral blood BKV PCR

$\mathrm{Pb}$ : peripheral blood

LR: likelihood ratio

CI: confidence interval

PCR: polymerase chain reaction

(1) Sensitivity: 78.4\% (95\% CI: 64.7-88.7), Specificity: 50.7\% (95\% CI: 38.4-63.0)

${ }^{(2)}$ Intensity of amplification: 1 (weak); 2 (intermediate); 3 (strong)

(3) Sensitivity: 31.4\% (95\% CI: 19.1-45.9), Specificity: 79.7\% (95\% CI: 68.3-88.4)

Prevalence of BKV in peripheral blood: 42.5\% (95\% CI: 33.5-51.9). 
BKV-viremia among the studied patients. In this study, strong urine BKV amplification (3+) achieved a LR of 2.8 predicting viremia, indicating a post test probability (PTP) of $67.5 \%$ (95\% CI: 1.61-4.89). The efficacy of DC for viremia prediction was not confirmed when taking into account CI achieved and its ability to improve the pre-test odds.

\section{DISCUSSION}

Early BKN diagnosis and reduction of the immunosuppressive therapy are the major strategies to improve graft survival and stabilize serum creatinine after kidney transplantation. ${ }^{18-20}$

The most important tool to establish this diagnosis depends on the graft pathological pattern, but the multifocal appearance in the parenchyma, the heterogeneous nature of viral inclusions, and the immunohistochemical findings compromise the accuracy of the anatomopathological BKN diagnosis. ${ }^{2,21,22}$ As a consequence, complementary and noninvasive tests, such as DC into the urinary sediment, viruria and viremia detection, and renal function follow up, ${ }^{9,19,22}$ can be important to early predict and manage nephropathy.

Among the population studied, the prevalence of DC, viruria, and viremia using these complementary tests were, respectively, 25\%, 62\%, and $42 \%$. Besides these high frequencies of BKV infection signals, ${ }^{5,21,23-26}$ this study also confirms the previous evidence of no clinical or histopathological characteristics associated with BKV infection. ${ }^{2,24,26,27,28}$

In agreement with others, ${ }^{26-28}$ there was no association with acute rejection or with its treatment. On the other hand, reinforcing the importance of an early diagnosis, no case of viremia among patients with current CAN highlights their probable severe renal damage hindering the viral replication. Another interesting finding was the lower prevalence of viruria among patients under treatment with sirolimus. This drug acts as an anti-proliferative agent and has been suggested as an alternative treatment for viral replication control in established BKV disease. ${ }^{30,31}$

Molecular detection of polioviruses has been considered as a gold-standard, and its efficacy has been confirmed by a variety of studies. ${ }^{2,13,24,32}$ Nowadays, regarding the countless different molecular techniques available for Polyomavirus detection, ${ }^{16,32}$ quantitative PCR with viral load definition is the most sensitive and specific approach. Urinary DC, considered as having the higher negative predictive value up to now, ${ }^{5,24}$ has been substituted by urine PCR. DC has a significant sensitivity for BKN detection, but PCR is up to 4 times more sensitive for viruria monitoring in asymptomatic patients, and also has the stability advantage upon the DC for that. ${ }^{32,33}$ However, not taking viruria into account, as suggested by some authors, ${ }^{34,35}$ can be contested. ${ }^{36}$ Despite the controversy, the uncommon occurrence of viruria or viremia among health people are due to JCV, a less uropathogenic agent. ${ }^{24,28,35,37-41}$ Hence, BKV viruria itself probably have clinical relevance.
The present study showed the urinary high BKV amplification intensity as the single test able to predict viremia occurrence $(3+; \mathrm{LR}=2.8 ; 95 \% \mathrm{CI}$ : 1.6-4.9). In this group, the presence of DC did not achieve clinical significance for viremia prediction $(\mathrm{LR}=1.55 ; 95 \% \mathrm{CI}$ : $0.8-2.9)$. Such finding becomes even more relevant due to the fact that viremia only occurs under active replication, not being observed during latent periods. ${ }^{15,42}$ BKV-PCR can be clinically used as a non-invasive test in order to identify kidney transplant recipients under risk or suspicion of BKN. Nickeleit and coworkers demonstrated that the viremia detection by seminested PCR can achieve up to $100 \%$ sensitivity and $88 \%$ specificity for nephropathy diagnosis. ${ }^{13}$ Quantitative-PCR has already defined some viral load cut-offs correlated with $\mathrm{BKN}$ risk: $>1.6 \mathrm{E}+04$ copies $/ \mathrm{mL}$ in plasma; $>2.5 \mathrm{E}+07 \mathrm{cop}-$ ies/mL in urine; $>7700$ copies/mL in total blood. ${ }^{24,43}$

There is a direct correlation between viremia load, graft dysfunction degree, severity of histological BKN tissue patterns, and number of infected renal cells in histological slide. ${ }^{37}$ Such correlation suggests that viremia occurs mainly, if not entirely, from the viral replication started in the kidney. This is the reason why the amount of viremia is more predictive of BKN than the viruria. ${ }^{16,24,44,45}$

Finally, viremia is a late BKV-infection event, associated with graft dysfunction and works as a marker for BKN development. ${ }^{28}$ It occurs 16 to 33 weeks previously to the establishment of $\mathrm{BKN},{ }^{13}$ and invariably appears later than viruria. ${ }^{36}$ Thus, an intense BKV-viruria predicts viremia, and probably BKN.

\section{ACKNOWLEDGEMENT/SUPPORT}

This work was supported by Coordenação de Aperfeiçoamento de Pessoal de Nível Superior (CAPES), Brazil.

\section{REFERENCES}

1. Agha I, Brennan DC. BK virus and immunosuppressive agents. Adv Exp Med Biol 2006; 577:174.

2. Duclos AJ, Krishnamurthi V, Lard M,et al. Prevalence and clinical course of BK virus nephropathy in pancreas after kidney transplant patients. Transplant Proc 2006; 38:3666.

3. Behzad-Behbahani A, Klapper PE, Valley PJ, Cleator GM, Khoo $\mathrm{SH}$. Detection of BK virus and JC virus DNA in urine samples from immunocompromised (HIV-infected) and immunocompetent (HIV-non-infected) patients using polymerase chain reaction and microplate hybridisation. J Clin Virol 2004; 29:224.

4. Takayama T, Miura K, Han G, Ushiyama T, Suzuki K, Fujita K. Bk virus subtype 1 infection associated with tubulointerstitial nephritis in a renal allograft recipient. Int J Urol 2004; 11:656.

5. Boldorini R, Brustia M, Veggiani C, Barco D, Andorno S, Monga G. Periodic Assessment of urine and serum by cytology and molecular biology as a diagnostic tool for BK vírus nephropathy in renal transplant patients. Acta Cytol 2005; 49:235.

6. McNees AL, White ZS, Zanwar P, Vilchez RA, Butel JS. Specific and quantitative detection of human polyomaviruses BKV, JCV, and SV40 by real time PCR. J Clin Virol 2005; 34:52. 
7. Gupta G, Shapiro R, Thai N, Randhawa PS, Vats A. Low incidence of BK virus nephropathy after simultaneous kidney pancreas transplantation. Transplantation 2006; 82:382.

8. Randhawa PS, Finkelstein S, Scantlebury V et al. Human polyoma virus-associated interstitial nephritis in the allograft kidney. Transplantation 1999; 67:103.

9. Ding R, Medeiros M, Dadhania D et al. Noninvasive diagnosis of BK virus nephritis by measurement of messenger RNA for BK virus VP1 in urine. Transplantation 2002; 74:987.

10. Vats A, Randhawa PS, Shapiro R. Diagnosis and treatment of BK virus-associated transplant nephropathy. Adv Exp Med Biol 2006; 577:213

11. Liptak P, Kemeny E, Ivanyi B. Primer: histopathology of polyomavirus-associated nephropathy in renal allografts. Nat Clin Pract Nephrol 2006; 2(11):631.

12. Ramos E, Hirsch HH. Polyomavirus-associated nephropathy: updates on a persisting challenge. Transpl Infect Dis 2006; 8:59.

13. Nickeleit V, Hirsch HH, Binet IF et al. Polyomavirus infection of renal allograft recipients. J Am Soc Nephrol 1999; 10:1080.

14. Tong CY, Hilton R, MacMahon EME et al. Monitoring the progress of BK virus associated nephropathy in renal transplant recipients. Nephrol Dial Transplant 2004; 19:2598.

15. Drachenberg CB, Hirsch HH, Ramos E, Papadimitriou JC. Polyomavirus disease in renal transplantation review of pathological findings and diagnostic methods. Hum Pathol 2005; 36:1245.

16. Si-Mohamed A, Goff JL, Désiré N, Maylin S, Glotz D, Bélec L. Detection and quantification of BK virus DNA by real-time polymerase chain reaction in the LT-Ag gene in adult renal transplant recipients. J Virol Methods 2006; 131:21.

17. Racusen LC, Solez K, Colvin RB et al. The Banff 97 working classification of renal allograft pathology. Kidney Int 1999; 55(2); 713-23.

18. Kuypers DRJ, Vandooren AK, Lerut E et al. Adjuvant Low-dose Cidofovir therapy for BK polyomavirus interstitial nephritis in renal transplant recipients. Am J Transplant 2005; 5:1997.

19. Hariharan S. BK virus nephritis after renal transplantation. Kidney Int 2006; 69(4):655.

20. Zavos G, Gazouli M, Psimenou E et al. Polyomavirus BK infection in Greek transplant recipients. Transplant Proc 2004; 36:1413.

21. Lee KW, Lee HH, Lee DS et al. Polimerase chain reaction for the diagnosis of human Polyomavirus-associated nephropathy in renal transplant recipients. Transplant Proc 2004; 36:2116.

22. Drachenberg CB, Papadimitriou JC, Hirsch HH et al. Histological patterns of polyomavirus nephropathy: correlation with graft outcome and viral load. Am J Transplant 2004; 4(12):2082.

23. Ginevri F, Azzi A, Hirsch $\mathrm{HH}$ et al. Prospective monitoring of polyomavirus BK replication and impact of pre-emptive intervention in pediatric kidney recipients. Am J Transplant 2007; $7: 2727$.

24. Hirsch HH, Knowles W, Dickenmann M et al. Prospective study of Polyomavirus type BK replication and nephropathy in renal-transplant recipients. N Engl J Med 2002, 347:488.

25. Bodin BC, Burel MC, Hourmant M, Sebille V, Garnier EA, Marcille BMI. A prospective longitudinal study of BK virus infection in 104 renal transplant recipients. Am J Transpl 2005; 5:1926.

26. Fogeda M, Munõs P, Luque A, Morales MD, Bouza E. Crosssectional of BK virus infection in pediatric kidney transplant recipients. Pediatr Transplant 2007; 11:394.
27. Ginevri F, Santis R, Comoli P et al. Polyomavirus BK infection in pediatric kidney-allograft recipients: a single-center analysis of incidence, risk factors, and novel therapeutic approaches. Transplantation 2003; 75:1266.

28. Hayson L, Rosenberg AR, Kainer G et al. BK viral infection in an Autralian pediatric renal transplant population. Pediatric Transplant 2004; 8:480.

29. Rocha PN, Plumb TJ, Miller SE, Howell DN, Smith SR. Risk factors for BK polyomavirus nephritis in renal allograft recipients. Clin Transpl 2004; 18:456.

30. Wali KR, Drachenberg C, Hirsch HH et al. BK Virus-associated nephropathy in renal allograft recipients: rescue therapy by sirolimus-based immunosuppression. Transplantation 2004; 78:1069.

31. Benavides CA, Pollard VB, Mauiyyedi S, Podder H, Knight R, Kahan BD. BK-virus-associated nephropathy in sirolimustreated renal transplant patients: incidence, course, and clinical outcomes. Transplantation 2007; 84:83.

32. Randhawa P, Shapiro R,Vats A. Quantitation of DNA of Polyomaviruses BK and JC in Human Kidneys. Journal Infect Dis 2005; $192: 504$.

33. Kapila K, Nampoory MR, Johny KV et al. Role of urinary cytology in detecting human polyoma BK virus in kidney transplant recipients. A preliminary report. Med Princ Pract 2007; 16(3):237.

34. Marinelli K, Bagnarelli P, Gaffi G et al. PCR real time assays for the early detection of BKV-DNA in immunocompromised patients. New Microbiol 2007; 30:275.

35. Arthur RR, Dagostin S, Shah KV. Detection of BK virus and JC virus in urine and brain tissue by the polymerase chain reaction. J Clin Microbiol 1989; 27(6):1174.

36. Vera-Sempere FJ, Rubio L, Moreno-Baylach MJ et al. Polymerase Chain Reaction detection of BK virus and monitoring of BK nephropathy in renal transplant recipients at the University Hospital La Fe. Transplant Proc 2005; 37:3777.

37. Drachenberg CB, Hirsch HH, Papadimitriou JC et al. Polyomavirus BK versus JC replication and nephropathy in renal transplant recipients: a prospective evaluation. Transplantation 2007; 84:323.

38. Ling PD, Lednicky JA, Keitel WA et al. The dynamics of herpesvirus and polyomavirus reactivation and shedding in healthy adults: a 14-months longitudinal study. J Infect Dis 2003; 187:1571.

39. Jin L, Pietropaolo V, Booth JC, Ward KH, Brown DW. Prevalence and distribution of $\mathrm{BK}$ virus subtypes in healthy people and immunocompromised patients detected by PCR-restriction enzyme analysis. Clin Diagn Virol 1995; 3:285.

40. Dolei A, Pietropaolo V, Gomes E et al. Polyomavirus persistence in lyphocytes from blood donors and healthy personnel of a blood transfusion centre. J Gen Virol 2000; 81:1967.

41. Dorries K, Vogel E, Gunther S, Czub S. Infection of human polyomaviruses JC and BK in peripheral blood leukocyte from immunocompetent individuals. Virology 1994; 198:59.

42. Reploeg MD, Storch GA, Clifford DB. BK virus: a clinical review. Clin Inf Dis 2001; 33:191.

43. Viscount HB, Eid AJ, Espy MJ et al. Polyomavirus polymerase chain reaction as a surrogate marker of polyomavirus-associated nephropathy. Transplantation 2007; 84:340.

44. Funk GA, Steiger J, Hirsch HH. Rapid dynamics of polyomavirus type BK in renal transplant recipients. J Infect Dis 2006; 193:80.

45. Hymes LC, Warshaw BL. Polyomavirus (BKV) in pediatric renal transplants: evaluation of viremic patients with and without BK associated nephritis. Pediatr Transplantation 2006; 10:920. 